Ewa Szczęsna*

University of Warsaw

\title{
LITERATE EXISTENCE IN THE DIGITAL SPACE. CONTEMPORARY TRACES OF IDENTITY ${ }^{1}$
}

\begin{abstract}
The aim of this study is to present how the development of writing technology influences writing itself. In this paper the analysis is focused on mechanisms of reinterpretation of writing and reading in digital space, in other words, the change in experience of text. To summarize, modern media techniques make reading become writing, when writing becomes clicking (an action taken upon the texture), and clicking becomes the experience of text. Another goal is to present a special role of the texture as the tool of text's creation as well as the place of cohesion. The importance of semiotic tissue of digital text, especially in the case of digital art, is visible in the formation of intratextual relations. These relations are created in the process of working one element of texture onto another, which allow them to play an important role in the creation of textual meaning.
\end{abstract}

Key words: identity, digital space, experience of text, textual meaning, intratextual relations

\section{Reading is writing. Writing is clicking}

The topic of writing as a way of living in relation to the digital culture evoke, first of all, problems connected with the prevalence of communication in the public domain, globalization of the individual record, the changing relation between literacy and orality - shaping of the new forms of linguistic existence as well as the development of new text genres.

* Faculty of Polish Studies, Univeristy of Warsaw, ul. Krakowskie Przedmieście 26/28, 00-927 Warsaw e-mail: e.k.szczesna@uw.edu.pl

1 This publication is part of the research project NN 103398340 funded by the National Science Centre in Kraków. 
The change in communicational behavior in the virtual world, transgression that takes place in text-user relation, inseparability of transciver activities - all of it significantly influence the existence of text. As a result, reading becomes writing (an action), writing becomes clicking, and clicking becomes the way of experiencing text through the texture.

Within digital culture the reception of text is a corporeal experience already at the perception level. There raises the question if clicking as a technical action, marking, selection of textual elements on the screen of computer, e.g., during reception of a hypertext novel, can be recognized as an action analogous to page turning during the reception of a novel preserved in the medium of a traditional book? At first glance, it may appear so. The opening of a book and page turning are undoubtedly technical conditions of reading. The counterpart of such experience in domain of digital culture is very act of clicking - I mean the act of key pushing and mouse clicking, moving cursor on the screen or marking and shifting elements on the touch screen with one's finger.

In my opinion, similarities end here. Page turning and clicking are connected with different intentions in domain of the recipient activity - the influence of a reader on the exhibition of text. Actions of turning and putting pages are connected with fulfillment of the intention of the only way of reading - by constructing text (creating record) author establishes a certain order of reading (in conventional word-composed text the order of record is the order of reading). This order, in case of e.g., a book consisted of novel text, is set by convention (various in different cultures) generated during development of writing culture along with paper information carriers. Conventionalization of the order of writing has lead to its transparency, which had been being disrupted every now and then by the creative interventions of authors. Experimental works that took degeneration from this principle as a subject of artistic activity (e.g., Hopscoth by Cortázar or works of Stanisław Czycz) emphasized the creative potential contained in the medium, the ability for additional textualization of the texture.

In traditional text not only author but also the reader was able (and still is) to not follow the principle of linear reception. A defiant reader or an impatient one can read selectively, fragmentalize the texture, however, in view of the current standards, such reading is still considered a fault (error in reading). Moreover, it's eradicated (especially by the school teachers who teach detailed reading with use of detailed tests regarding contents of books). Thus deviation from the reading norm comes from the readers themselves, those who cannot wait for the answer "who is the killer?" or "if he and she will live happily ever after?" and interrupt the 
reading in order to take a peek at the last page of a novel. Another group of defiant readers is consisted of young receivers adjusted to the culture of news, flashes, SMS, and twitts. They tend to skip the extensive description passages in multi-volume two-centuries-old novels because of lack of the reader's patience.

Still, there is another type of interference in reading order. Its example is provided by the reception of philosophical works (i.a., Ecce Homo of Nietzsche) which Stanisław Ignacy Witkiewicz has made ${ }^{2}$. It is indicated by the handwritten marking of text fragments, reader's annotations in the margins and interlines, the ironical, the mocking as well as those serious ones. Every single one of these activities indicates the existence of reader's need to interfere in the text, experiencing it, modeling and familiarizing someone else's text, inscribing own interpretational activity in its tissue. Witkacy in view of his reception of philosophical works (and probably not only him) was a prototype of the user.

Besides, there are books that are more or less supposed to be read selectively, not necessarily in order of following pages. I mean not only holy books, encyclopedias, dictionaries or cooking books and guides but also volumes of poetry, collections of aphorisms and sentences. No longer in principle, but more often it happens also in case of reception of dissertations and philosophical treatises. Eriksen in Tyranny of the Moment wrote about shortening and simplifying dictated by the quick passage of time, hegemony of fragment (Eriksen 2003), which this scholar sees as an effect of information overload and compulsion to constant actualization of it.

Fragmentalizing kind of reader, for whom reading becomes usage, remaking, therefore text writing, is also being shaped by contemporary mass media that are striving for his attention and competing in its appropriation. Press market should serve as good example. Semiotic method of article composition - emphasizing the most important fragments with bigger, bold font, sometimes with red color, placing them in separated, eye-catching places on the plane of newspaper page. Numerous illustrations encourage to fragmental reading, replacing solid, linear reading with browsing ${ }^{3}$. Selective reading performed by reader is texture modification devoid of any fixation.

2 This reception was received at the exhibition Marginalia filozoficzne that was organized in the Contemporary Art Center in Ujazdów Castle in Warsaw (19.01-22.02.2004, curator: Paweł Polit).

3 Browsing as a reading method is being analyzed by myself in a chapter entitled "Komparatystyka mediów. Poetyka, semiotyka, komunikacja medialna" published in a book Komparatystyka dla humanistów (Dąbrowski 2011: 289-312). 
Specified manifestations of reading insubordination, in regard to reception in digital media, illustrate the phenomenon of perceptual and mental overwriting of reader's own text on the existing one (with use of this text's elements). Thus reading becomes writing or rather overwriting text on another text. It is creation of palimpsest that becomes fixated (just like in Witkacy's case but also in case of scholar's method of reading other scholar's books with pencil in a hand) or (what happens more often, even in the case of reception of magazines) is never fixated, lasting only as sort of mental palimpsest.

Reading mechanisms that in case of traditional book usually had a status of experiment or even aberration are set as standard in case of digital transitions. They are recognized as a principle of reading. This mainly concerns the selection category as well as adding and commenting. Such activities set multivariate existence of text. Meaning, choice of textual element, order of texture revealing, commenting, adding textual element - all of those are traces of reader's presence in text. In contrast to the traditional text, they are not vigilante actions, but become inscribed in the sender intention of the author. They are being foreseen and designed by computer.

Reader's selection of texture elements is very essence of hypertext. It's experience of written reading, reception that is writing at the same time and the texture of which stops being untouchable, but becomes a place of creative activities. Otherness of receiver activity is reflected in the category of text usage.

The text reading method changes along with development of digital culture. Research led by neurologists and perception psychologists shows that browsing internet pages, reception of text in the plane of computer screen goes in a jumping manner. Content on a computer screen is taken differently by persons shaped in the tradition of the printed book and differently by persons adjusted to tradition of the new interactive media. In the first case skipping has lesser frequency and receiver's gaze lasts longer at each fragment of text, following linear manner of its progress - in the latter case, the frequency of attention diverting rises drastically, and its span towards single elements decreases. Therefore, cause and effect thinking, coherent narratives, sequences of events development - all elaborated by the writing tradition - are replaced by associational thinking.

The issue of influence of the communication technologies on the way of how we experience text (act of constructing such experience and elaborating a certain type of perception) has been discussed many times by researchers. As an example, let's invoke thoughts of Derrick de Kerck- 
hove, who pointed out connection between literate mind and tendency to manipulate concepts, processing information more in mind than in acting, relying more on words than on the images (Kerckhove 1985). He contrasted these features with an oral mind which he attributed (just like Ong) to associational thinking, focusing on reconstructing of imaginary, putting emphasis on memory, inventing metaphors and creating myths. Digital communication do not separate these ways of thinking. It connects them, confronts them as well, and sets in motion mutual interactions. As a result, experience of digital transmission is not only a polisensoric experience but also it reinterprets the existing epistemological order of text. Such reinterpretation appears to go beyond oralitzation and iconization of writing, literacy of speech and image $\mathrm{e}^{4}$ indicated by the scholars. Rather, it means seamless interaction of various forms of perception and orders of text structuring - though, it should be mentioned that these orders are different in view of contemporary technologies, not in the view of digitalism, for which they create coherent system and subject to the same laws.

The change in method of text reception do not necessarily mean the abolishment of coherence (semantic coherence), which in case of traditional text is supported by formal coherence (linear one). In case of digital transmissions the main factor supporting coherence is the kind that I define as semiotic coherence. The method of reading and meanings constructing in digital transmissions is quite often decided by the organization of signs of transmission on the computer screen. This coherence may be real, when sign elements are organized in such order that by determining the order of reception, they provide entirety with a specified meaning. Coherence may be illusory as well - when the order of sign elements on the screen makes semantically distant elements appear coherent for the user. It is worth noting that semiotic coherence, especially playing with this coherence and its interferences, is organizing digital art quite often.

The way of how text is presented is not a transparent medium, it becomes text itself. It is visible at the level of font. E.g., Diane Gromala has projected font of eclectic nature - its combination of various types of traditional and modern fonts. Excretia - that is the name of the project - has dynamic nature - the size of letters may change continually before the eyes of the viewer, participating in creation of textual meanings, which show their

4 See M. Sndbothe. "Transwersalne światy medialne. Filozoficzne rozważania o Internecie”, K. Krzemieniowa, tran., Widzieć, myśleć, być. Technologie mediów, selecion and development by A. Gwóźdź. Kraków, 2001, p. 215-222. 
unstable nature already on the stratum of represented objectivities. This constantly fluctuating letters are traces of many identities that constitute every writing one.

With Excretia, a Word processor is no longersimply a productivity tool but a reflective experience in itself. As the writer works, he sees how his biofeedback reshapeshis words. (...) Excretia makes writing truthful in the ironic sense that it reveals the writer'sbodily states. (...) Writing can be reflective interface, a mirror of the author, although not a perfect mirror because our written identity is different from who we are when we are speaking casually. In fact, we have many written identities, as we write in different voices for different audiences and different purposes (Bolter, Gromala 2005: 166, 168).

The change in reading method is physical commitment of receiver to the tissue of text. Touch, corporeality are participating in creation of texture. Receiver of traditional text in a form of a book has no ability of interference in the tissue of text. He takes text as it was proposed. His creative activity is engaged only at the level of interpretation. It is reflected in Steven Knapp's (Knapp 1993) concept of literature as well as in Martha Nussbaum's one, according to which (what Jonathan Culler notes) all literary narration techniques are eventually transforming readers into judges evaluating characters' choices, analyzing factors that were not affecting (Culler 1013).

\section{Clicking is experiencing the text in texture and through it}

In case of hypertext the attitude of "literary judge" recedes into the background, making place for attitude of "the perpetrator of the text event" and as a result, the perpetrator of the world that said text stands as. Digital transmission enables acting, even more, it requires acting, experiencing text and its efficacy. Clicking launches the text event and decides its way of existence. Texture gains status of textual experience object. It's experienced in physical way. It's especially evident in various projects - installations spacializing text and connecting it with receiver's body, where experience of writing is the experience of creating text with a whole body.

Written word is not only a tool of thought externalization anymore, a method of fixating them (Eriksen 2003), but it becomes an object of textual actions alone, an object of receiver's experience. Clicking is writing - causing text, organizing the way its appearing. It sets in motion perfor- 
mative power inscribed in linked word. A thing connected with acting is the act of immersion that researched especially in the view of video games but also - wider - in the context of narration (Ryan 2001) is described as a kind of receiving experience involving submergence in a diegetic world (Murray 1997: 98). In case of digital transmissions the semiotic layer of text along with user acts are engaged. Diegetic world becomes present yet at the level of texture, what causes immersion act to get coupled with an aesthetic experience.

In a digital environment the sign and text are experienced not only through eyesight and hearing but also through touch. Speaking about experiencing instead of perceiving is justified in the act of user's actions taken on the texture - both on individual signs and on whole texts.

Sign and text are analogous relation structures. In both cases we encounter meaning established in the act of reception, the main impulse of which is stratum of represented objectivities external to the cognizing subject. The main difference between the sign and the text is based on the degree of complexity of the elements of relations. Semiotic textures of the sign and the text differ, broadly speaking, in levels of complexity that becomes apparent in the process of meaning establishing (interpretation). The sign's stratum of represented objectivities is constructed in such way that it usually gives a single impulse to creation of meaning in the process of reception. It's different in the case of text where establishment of meanings requires determining the semantic relations that connect more complex units - aspects, events and even whole plots. An example for this may be provided by series of novels, TV series and advertising campaigns that are politexts where the global meaning is constituted in the interaction of many texts.

The texture (a semiotic tissue of text), is a factor of culture text perceived sensually - through sight, hearing, touch - usually somehow fixated (record, e.g., verbal, score, iconic, audiovisual one), organized in a particular way (genre-specific). The texture of a particular work is a closed set of specified elements with their own composition. In the case of conventional text this closed nature of texture remains contrasted to variously conditioned interpretation variables over time. As such texture it sets the basic boundaries of text.

There are textures that do not have any fixation by rule (e.g., musical improvisations, theatre plays) but they may be still possible to record (secondary fixation). Example may be provided by audiovisual records of sand painting uploaded to the internet (available on YouTube), we can invoke here the works of Ksenia Simonova or Ilana 
Yahav $^{5}$, records of spectacles or musical improvisations. It must be noted that such record is only a remediation creating a new text.

Texture has its own technological and formal dimensions. It means that it's created with help of specified technologies - medial tools, e.g., writing, print, photography as well as audio, audiovisual and interactive technologies. Also, it means that typological information is communicated already at the level of texture - information regarding generic form of text, thus creating architext (Genette 1982).

The ability to recognize the majority of generic forms already at the level of perceptual reception are obtained by the receiver through cultural participation. In brief, already at the level of perceptual reception we can see, without any necessity to delve into the semantics of communication, that specific text is a poetic work, prose, movie poster, a comic, newspaper article, visual advertisement, a movie, theatre play, blog, a video game or a literary hypertext.

Composition of texture elements, semiotic organization and technology provide us with indicators of generic and typological information. E.g., the arrangement of printed words into lines and strophes (strophoids) is carrier of information telling us that we are dealing with a poem. Continuous arrangement of words with marking of dialogues and extraction of the chapters should be associated with prose. In turn, the division into columns, presence of lead, photos with captions, characteristic format of a page should invoke newspaper article. Presence of interface, links, possibility to take action on the texture while maintaining traditional generic traits indicates that conventional text has been digitally remediated.

Texture is the place and a tool used to create meanings that are formed in the active intellectual confrontation with cognizing subject. The meanings created by subject are initiated by texture (in the situation of text reading) or coded in it (in situation of text writing). Both activities are of creative nature. They are separate, but sometimes become connected as well. They cannot be opposed to each other for sure. Good example is provided by the activity of a translator, critic, cultural historian (researcher of literary text, document, iconic or musical message). Every of those activities is activity of an interpreter, who is first provided by the texture with an impulse to creation of meanings, to begin an interpretational work, then it transforms texture into text that is getting encoded in the new texture afterwards.

\footnotetext{
5 See. www.sandstory.com
} 
In a digital environment previous semiotic forms and medial structures are subjected to remediation. As a result, polisemiotics, multimediality, and palimpsest-like nature of digital texture confronted with previous media can be seen as elements of different systems. Subjected to remediation, in digital space they are complementary elements of a single medial system, where the foundations of said community are placed in immaterial matter of texture, ontic identity of every digitally generated texture element.

An important factor is also the change in the range of activity of a subject that stands as text in the process of texture reception. The stability of a texture is characteristic for analog culture. Except the situations regarding textual experiments, the texture is generally given to receiver in specified, single form without possibility of any change within. It is set as arbitrarily complex sign (untouchable exhibit) that provides impulse to meanings establishing. Its important feature is immutability. The only possible reconstructions and renovations are not receiver's actions but corrective proceedings aimed at restoration of the original. Receiver's activity is possible on the stratum of meanings, interpretations, thanks to which it attains its variability. Maybe it's the immobility of the texture that became the basis of theories regarding specified meaning encoded in text, meaning that is meant to be reached by the receiver.

In case of the digital transmission the receiver is experiencing text both at the level of meaning and texture. The important change in the ontics of texture is its mobility, the ability to make changes in texture. User's work on texture is programmed activity, where this programming concerns the existence of a set of possible actions taken on the text. Action or inaction, the order of operations, the selection of elements, appending them, adjusting and skipping - all of these remain the responsibility of the user. Causing a specified forms of texture by user - varied by users and usually different during subsequent acts of reading - is an important factor in the differentiation of meanings.

In the era of the internet the universality of daily activities on a digital texture is a necessary condition for the fortunate participation in social life - becoming a way of living itself. The economic function of the texture strengthen ups. It serves not only as a transparent medium of meaning but also as a carrier of metatextual meaning, generic information, matter of superstructural texture and a text tool. The changing form of texture, its immateriality in the world of digital media, the reinforcement of other roles beside the basic one - role of the transparent carrier of meaning, reflecting the new identity of text and its user. 


\section{Texture functions in the era of a new identity of the text}

Texture is still seen primarily as a transparent medium for meanings. This feature is one of the most fundamental ones, especially in the case of conventional texts. It's connected with an informational function of text, with focusing attention on communicating meanings (the invention of print, photography, cinematography, internet were associated primarily with fixation and transmission of content).

Techniques of recording, reproduction and distribution of verbal, iconic, auditory and audiovisual information are focused primarily on making the texture independent from time and space. It should be emphasized that this independence applies precisely to the texture rather than meaning, the multiple factors of which (for example, related to the predispositions of cognizing subject) are making it only partially stable. In principle, stability of texture as the impulse to creation of textual meanings is the sole guarantor of the relative stability of the text. This stability, tangibility and verifiability of texture (as opposed to variable in its essence, in many ways conditioned interpretation) was the basis of universal identification of texture with the text.

In the consciousness of an average participant of culture text is indentified with the texture (e.g., of novel, film, newspaper article or any other message), the receiver of which assigns it some specified, generally single meaning. The higher repeatability of texture form and the farther its ossification has advanced, the greater its transparency. About such transparency we should speak in case of conventional book, where repeatability of the same typographical solutions, the same principle of organizing verbal, iconic and graphic elements has led to texture becoming transparent. The idea of texture transparency is organizing a realistic art as well - in its various semiotic and medial forms - both realistic art and photography, literature and film. It also organizes methods of digital transmission, in particular, all those who are focused on the timely establishment of specified textual meanings by the receiver. News services, portals and online forums - in short, all these forms that are aimed at communicatory aspects will strive to maximize the transparency of texture while making it carrier of a generic information at the same time. Organization of texture should enable user to recognize the textual form and establish meanings through interactive interpretation.

The function of texture as a transparent medium refers to the digital textures, no less than to texts of print culture or analog audiovisuality. The difference is that in the case of interactive media, the texture of the 
dominant transparent medium includes within itself also interactive tools and actions. Here we encounter a peculiar paradox. On the one hand, the transparency requires simplification, reduction of texture forms, limitation of its variations so the solid forms can crystallize, on the other hand provided by digital technologies countless amount of texture modifications in the area of colors, graphic forms, arrangement of elements in the plane of screen, sound effects or kinetic forms is opposed to transparency.

Texture serves also as a carrier of matatextual meaning (a multidiscursive texture). In this case, its transparency is distorted to some extent. Multidiscursive texture calls for the attention of the recipient, stimulates him intellectually, makes him a dialogue partner, very often it introduces a game between discourses (such as The Holy Sinner by Thomas Mann, Jacques the Fatalist by Denis Diderot, If on a Winter's Night a Traveler by Italo Calvino, or Fantomas contra los vampiros multinacionales Julio Cortázar) and confronts them dialogically.

Texture's function as a genreic information carrier is realized in the fact that every texture has characteristics that are indicators of formal affiliation of the text. This includes semiotic, medial and compositional features of texture elements that already at the level of perceptual reception, without penetrating the semantic layer of text, allow us to identify the text form (generic and typological affiliation of text).

A situation where semiotic tissue of text is not a transparent medium of textual meanings, but creates an additional message, the meaning of which usually come in the interpretative relationship with semantics of the text, describes the texture, which becomes a matter of superstructural texture. A good example of implementation of such function is provided by the concrete poetry, in which the verbal texture, beyond being a carrier of a textual meanings, is also an iconic text. The same happens in the case of works of digital art. In "TextRain" (Camille Utterback, Romy Achituv) letters arrange in words that are carriers of semantic meanings, but they are also carriers of the superstructural contents - letters, falling at the body of the receiver, are arranging themselves in words, indicating in a symbolic way the participation of culture user in shaping textual meanings and text itself.

In the digital space one of the most important functions of texture is the function of the text tool. That function is performed primarily by the texture elements belonging to the tool framing of text (elements of a graphic interface) but also the elements located in text plane (e.g., linked words, icons). The greater variety and variability of textual tools' forms, the lower their transparency. In turn, the repeatability of the same tools causes the receiver to become indifferent, makes them transparent for him. 
In case of texture elements that are textual tools, where texture becomes a field of user's textual operations, his focus gets shifted from looking through texture to looking at it. As Bolter writes, this shift or rather oscillation between transparency and opacity, looking "through" and "at" was present already in the print culture, in modernist literature that was moving the focus from the text as a history to the text as a structure of allusions (Volter 2011: 185).

It is worth considering the relationship between the function of the text tool and metatextual function. Both are connected by the reference not to the presented world created by the text but to the text itself. But while metatext refers to the meanings - is anchored in the act of interpretation, becoming an interpretation made present, the function of action in hypertext refers above all to the tissue of text.

When confronted with the theory of speech acts, the function of text tool (action) invokes implementing acts - performative ones that not only do not subject to the criteria of veracity but also establish facts in reality. But while speech acts demonstrate how words refer to extra-linguistic reality, the function of operations shows how words and other meaningful text elements can operate with other words and other elements of texture. Activities in hypertext, such as moving, recalling, selecting, cutting and pasting are activated by the direct actions on the texture. In case of digital communication the arbitrary elements of texture (words, icons) are stamped with function of meaning causing within the text. This makes it possible to speak about specific intratextual communication - in which communicational interactions between the texture elements within a single text take place.

The way of existence of texture in the literary hypertext leads to considerations regarding the category of intratextuality. The possibility of breaking apart the textual elements (atomization) setting them in motion, connecting them and hypertextually bonding reveals intratextual relations - interactions regarding elements within the text. With the development of digital communication (also digital art) the microcosm of text grows as well and its elements are set in motion of interaction. Microcosm of the text can be described in a confrontation with its macrocosm, which is undoubtedly constituted by the intertextual relationships - all forms of "going beyond" an individual text, establishing relationships with the other text. The example of intertextual practices, which participate in creation of text's macrocosm, are all structures of textual relations: translations, adaptations, quotations, paraphrases, allusions, parodies, travesties, pastiche - and both ones regarding content elements of text and formal elements (textual structures). 
The function of communication subject is connected with text tool function. It is realized in participation in dialogical relations with the user and is inscribed into texture of programmed and simulated activity of text as a dialogical partner, interlocutor. Such dialogue is established by the rules governing specific textual form: it requires user to know the rules of using the digital texture.

The hypertext texture can cumulate functions listed above. This is especially true in the area of art open to multiple interpretations. In the literary hypertext Blueberries by Susan Gibb the words-links are transparent carriers of meanings, but at the same time its transparency is limited by the mobile color fluctuating under the influence of user's actions. Iconic elements are creating texture build up on the word, they create text of metaphoric value. Violet is associated with the image of berries appearing in the memories of heroine and the memory of sexual abuse back in childhood that is associated with them. The change in words' color into grey (after clicking them) is the symbol of futility of efforts leading to erasing of the traumatic memories. Linked words function as a medium of meanings, matter of superstructural texture and text tool. Accumulation of the texture functions, some of which are related to transparency (function of the medium of meanings) and others, on the contrary, are limiting it (a metatextual function) and cause some kind of tension, semantic and syntactic game, in which word labeled with many functions acquires the homonym status.

Semantization or even fabulariztion of semiotic tissue of text makes reading a direct experience of the presented world. Tissue of text is not a neutral medium, but a place where plot is present. The plot becomes apparent in the writing signs - in Blueberries the violet and grey words are signs of traumatic events from childhood that cannot be erased.

Even more clear exmaple of writing with body, engaging there receiver's body in texture is provided by the spacial projects - the already mentioned TexRain (Camille Utterback, Romy Achituv from 1999), project that is an adaptation of Zimroth's poem and inspired by concrete poetry of Appolinaire (Il pleut poem form 1918) or Still Standing (Bruno Nadeau, Jason E. Lewis from 2005) 6 . In Tex Rain touching letters, words, influencing their shape, the appearance of text are elements of designed user's activity. Kinetic units of text - words, letters are revealing new possibilities of meaning creation for language, writing seen as the tissue of text. While

6 Both projects were analyzed by Roberto Simanowski in the context of crossing generic boundaries and playing with text (Simanowski 2007: 35-53). The TextRain project was analyzed also by Jay David Bolter and Diane Gromala (Bolter, Gromala 2005: 12-15). 
Apollinaire in his Il pleut was performing reification or even iconization of words, drawing with them their meanings (rainfall painted with the word "it rains"); Utterback and Achituv are breaking words apart, saturating falling letters, words fragments with associations connected with rain. Words of the poem are becoming a rain itself. While Apollinaire's reader had to see the rain painted with word, now he has to experience the text falling with rain. Digital art is creating an intertextual kinetic metaphor.

The reception of a literary work means experiencing it in a physical way. It happens in interaction with texture in the process of meaning creation - reading again becomes writing. This time in the sphere of texture. In the sphere of interpretation - the authors are intentionally inscribing contextuality into the reading process. Construction of meanings has to happen in confrontation of digital project and works of Apollinaire'a and Zimroth but also in the static printed word and movable word in the digital sphere as well as experience of sense and experience of texture (in the poem by Zimroth appears a motif regarding conversation of two people that is the conversation including language of the body and language of words). In this context the reading becomes not only writing but also overwriting of meanings created as a result of confrontation between the meanings of various works, also, it becomes the experience of texture, mutual interaction of user and texture. It's stamping and constructing (or maybe cognizing) your own identity on a text in contact with the literary work.

In sphere of digital art signs of writing especially easily acquire status of textual actions. Subjected to iconization at the same time they become object and place of an experiment, experience of textual matter. The center of gravity is shifted from being transparent medium of content to being the matter of text - the matter to shape almost like in the case of sculpture.

Michaelo Angelo could see a shape of form in the marble blocks, a form that he - as he used to say - was only releasing from its imprisonment. Contemporary digital artists, including creators of digital literature, are noticing in letters, words, phrases a coexistence of many possible texts carrying various meanings that come together in a dialogue and are confronting each other. In such situation writing is coding multiplicity of meanings in texture, meanings that so far in traditional text could appear only in the situation of reading - at the level of interpretation. It's acknowledgment of the user's rights to co-creation of text already at level of its tissue; extraction of various forms trapped in texture. 
Digital art by making us co-creators of text appearing on the screen allows us to redefine our identity, extract it or reconstruct in the process of text co-creation. It enables us to imprint the trace of our own identity on texture. Furthermore, by engaging us both intellectually and physically in text experiencing, it proves that the famous opposition of culture and nature is simple misunderstanding. Cultural nature of a man described by humanists is natural to us in the highest degree - and certainly not less natural and linked with corporeality just like biological aspect.

Translated by Marek Ostrowski

\section{Bibliography}

Bolter Jay D. 2011, Writing Space. Computers, Hypertext, and the Remediation of Print, New York: Routledge.

Bolter Jay D., Gromala Diane 2005, Windows and Mirrors. Interaction Design, Digital Art, and Myth of Transparency, Cambridge MA: The MIT Press.

Culler Jonathan 2006, The Literary in Theory, Stanford CA: Stanford University Press.

Dąbrowski Mieczysław, ed. 2011, Komparatystyka dla humanistów, Warsaw: Wydawnictwo Uniwersytetu Warszawskiego.

Eriksen Thomas H. 2001, Tyranny of the Moment. Fast and Slow Time in the Information Age, London: Pluto Press.

Genette Gérard 1982, Palimpsests. La littérature au second degree, Paris: Éditions du Seuil.

Kerckhove Derrick de 1985, The Skin of Culture. Investigating the Electronic Reality, Toronto: Kogan Page Ltd.

Knapp Steven 1993, Literary Interest: The Limits of Anti-Formalism, Cambridge MA: Harvard University Press.

Murray Janet 1997, Hamlet on the Holodeck: The Future of Narrative in Cyberspace, Cambridge MA: The MIT Press.

Ryan Marie-Laure 2001, Narrative as Virtual Reality. Immersion and Interactivity in Literature and Electronic Media, Baltimore and London: The Johns Hopkins University Press.

Simanowski Roberto 2007, Digital Art and Meaning, Reading Kinetic Poetry, Text Machines, Mapping Art., and Interactive Installation, Minneapolis - London: University of Minnesota Press.

Gwóźdź Andrzej, ed. 2001, Widzieć, myśleć, być. Technologie mediów, Kraków: Universitas. http://www.youtube.com/watch?v=CamrO-9jjQo\&list=PL0AE2A2A6C6249B3C

http://www.youtube.com/watch?v=heMgid4rkzU

http://www.youtube.com/watch?v=oxbHrjoNfkA 